\title{
A INFLUÊNCIA DAS TECNOLOGIAS DIGITAIS NOS PROCESSOS DE ENSINO E APRENDIZAGEM DE LÍNGUAS
}

\author{
JEANNE JESUÍNO CARDOSO RODRIGUES ${ }^{1}$
}

Instituto de Letras e Linguística, Programa de Pós-Graduação em Estudos Linguísticos Universidade Federal de Uberlândia, Av. João Naves de Ávila, 2121 Uberlândia, MG - Brasil

jeannejcardoso@gmail.com

\begin{abstract}
Resumo. As ferramentas tecnológicas ampliaram nossa capacidade de comunicação, distribuição e compartilhamento de informações. A Internet trouxe consigo um universo novo, cheio de possibilidades e soluções. Contudo, muitas escolas e educadores ainda não conseguiram entender e trazer isso para suas práticas e salas de aulas. Este artigo propõe reflexões acerca das possibilidades que as tecnologias digitais proporcionam para o ensino e aprendizagem de línguas, em função da realidade digital que temos vivenciado em nossa sociedade. Precisamos repensar os processos de ensino e aprendizagem, não apenas para que o uso das tecnologias digitais seja normalizado, ou para que as escolas se adaptem à realidade digital do mundo fora dela, mas para que tenhamos conteúdos significativos para alunos e professores.
\end{abstract}

Palavras-chave: tecnologias digitais; ensino e aprendizagem de línguas; normalização.

\begin{abstract}
Technological tools have expanded our ability to communicate, distribute and share information. The Internet has brought with it a new universe, full of possibilities and solutions. However, many schools and educators have not yet been able to understand and bring this to their practices and classrooms. This article proposes reflections on the possibilities that digital technologies afford to the teaching and learning of languages in face of the digital reality that we have experienced in our society. We need to rethink our teaching and learning processes, not only for the use of digital technologies to be normalized, or for schools to adapt to the digital reality of the outside world, but in order to reach a meaningful content for students and teachers.
\end{abstract}

Keywords: digital technologies; language teaching and learning; normalization.

\footnotetext{
${ }^{1}$ Mestre em Estudos Linguísticos pela Universidade Federal de Uberlândia e professora de língua inglesa da rede municipal de Uberlândia.
} 


\section{A tecnologia e os nativos digitais}

Vivemos em uma época em que a tecnologia se tornou parte de nosso cotidiano. São smartphones, tablets, notebooks, aparelhos Bluetooth, recursos que há algum tempo não eram tão populares ou conhecidos como agora, e hoje até mesmo crianças já estão familiarizadas e os utilizam. Nessa realidade digital, quem não participa do Facebook, WhatsApp, YouTube, Skype ou mesmo acessa e-mails acaba sendo excluído dessa sociedade informatizada.

No Brasil, a Pesquisa Brasileira de Mídia 2015 (PBM 2015) comprovou que os jovens de 16 a 25 anos são os que passam mais tempo utilizando a Internet. Essa pesquisa foi realizada pelo instituto IBOPE, a pedido da Secretaria de Comunicação Social da Presidência da República (SECOM), para "compreender como o brasileiro se informa" (BRASIL, 2014, p. 7). Foram entrevistadas mais de 18 mil pessoas em todos os estados brasileiros durante o mês de novembro de 2014.

De acordo com esse estudo, $65 \%$ dos jovens com idade entre 16 e 25 anos estão conectados à Internet durante todos os dias da semana, enquanto apenas $33 \%$ dos adultos entre 36 e 45 anos de idade estão conectados com essa mesma frequência - número que cai ainda mais quando comparamos com os adultos de 46 a 55 anos, faixa etária em que apenas $20 \%$ utilizam a Internet todos os dias. Esses dados estão disponíveis no gráfico abaixo:

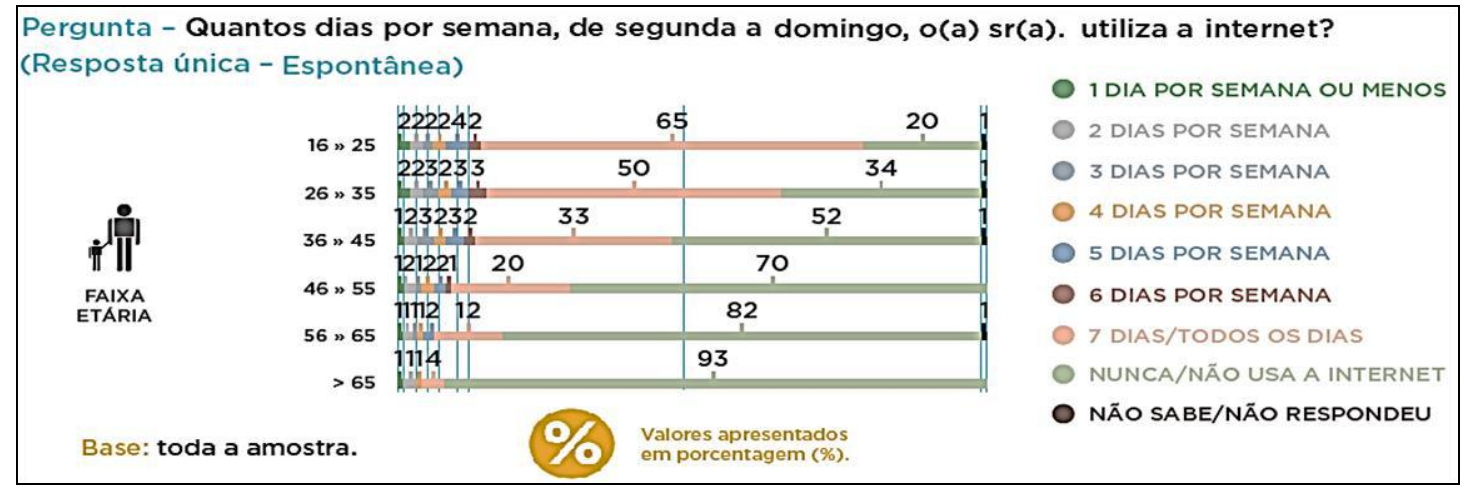

Gráfico 1. Frequência de uso da Internet por faixa etária. Fonte: extraído e adaptado de Brasil (2014, p. 53).

Em outra pergunta desse mesmo questionário, foi demonstrado que esses jovens de 16 a 25 anos passam, em média, 05 horas e 51 minutos/dia conectados à Internet de segunda a sexta-feira, e 05 horas e 25 minutos/dia aos finais de semana, conforme pode ser visto no Gráfico 2: 


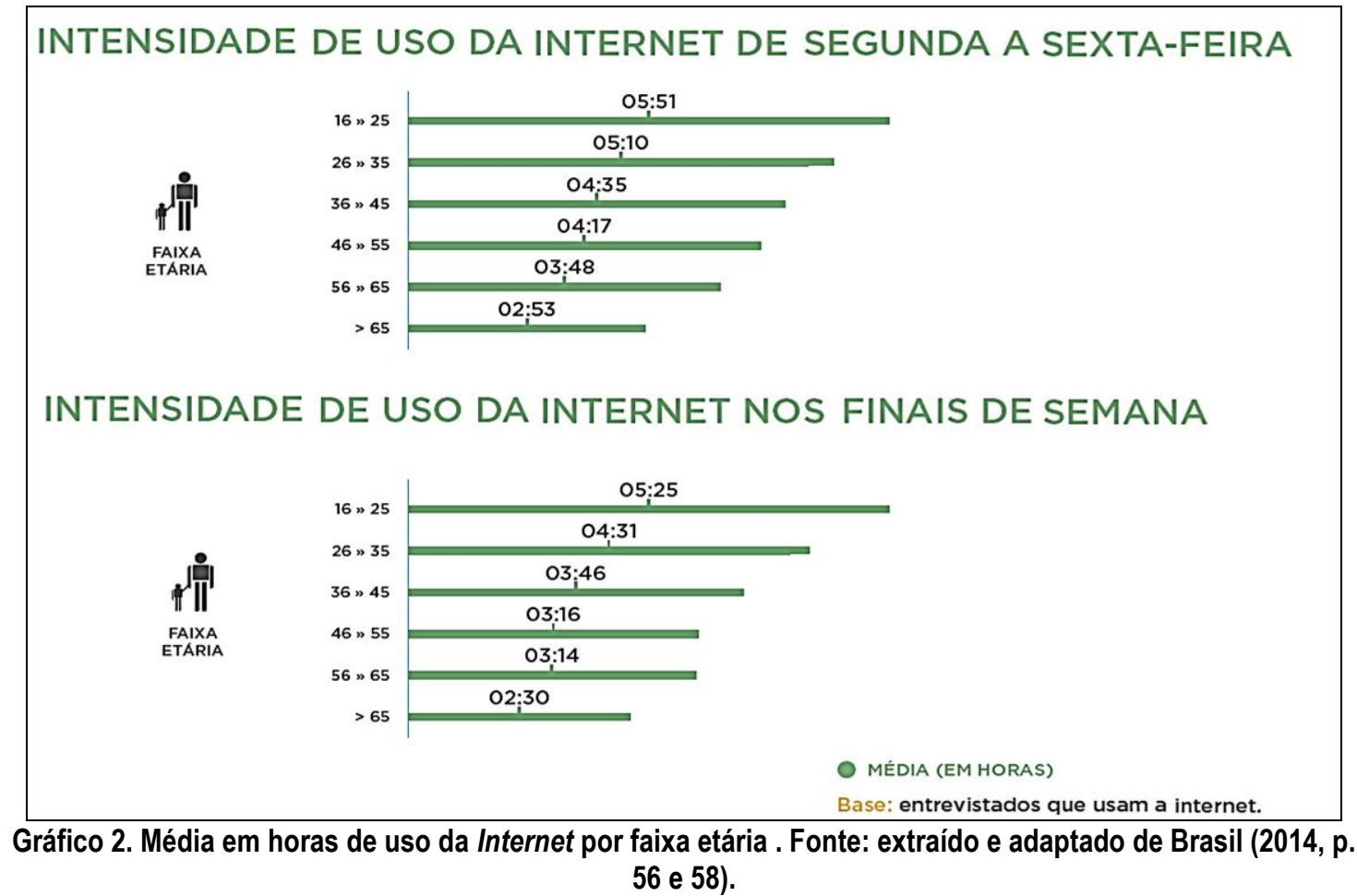

Considerando que essa média de horas se mantém e que eles passam três anos no ensino médio e mais quatro, pelo menos, na graduação, teríamos, ao final desse período, jovens que passaram mais de 14.500 horas conectados, consumindo, produzindo e compartilhando informações na rede. Ao contrapor a média de horas semanais dos jovens de 16 a 25 anos e a dos adultos de 36 a 45 anos, percebemos que esses jovens estão conectados, em média, 10 horas a mais por semana que os adultos, que seriam, teoricamente, seus professores.

Prensky (2001, p. 1) afirma que "nossos alunos mudaram radicalmente. Os alunos de hoje não são mais as pessoas para quem nosso sistema educacional foi desenvolvido ${ }^{2 "}$. Por conseguinte, torna-se fundamental repensar nossas práticas educativas, de modo a atender esses "novos" alunos que, segundo o autor, são os chamados "nativos digitais". Eles recebem esse nome porque estão imersos nessa era digital, rodeados por computadores, celulares, videogames, entre tantos outros recursos tecnológicos e, por isso, pensam e aprendem de forma diferente das gerações anteriores (PRENSKY, 2001).

Segundo esse autor, os nativos digitais podem aprender de forma bastante rápida, bem como conseguir realizar várias tarefas ao mesmo tempo e de forma paralela. Eles preferem gráficos a textos, gostam de estar conectados, esperam por gratificações e/ou recompensas, e preferem jogos a trabalho "sério" (PRENSKY, 2001, p. 2). Por outro lado, e ainda conforme Prensky (2001), os professores imigrantes digitais preferem ensinar um conteúdo de cada vez, de forma gradativa, lenta, passo-a-passo. Eles acreditam que seus alunos deveriam aprender da mesma forma que eles aprenderam, esquecendo-se que os alunos mudaram e que podem aprender de formas diferentes.

\footnotetext{
${ }^{2}$ Nossa tradução para: Our students have changed radically. Today's students are no longer the people our educational system was designed to teach.
} 
Ao tratar dos games na educação, Mattar (2010) nos traz um quadro comparativo entre os estilos de aprendizagem dos alunos do novo milênio e os do milênio anterior, que foi traduzido a partir do trabalho de Chris Dede (2005). Ele nos traz alguns dados interessantes sobre as diferentes visões que alunos de diferentes gerações possuem, e que corroboram o que tem sido discutido por Prensky $(2001,2006)$, como pode ser visto abaixo:

\begin{tabular}{|l|l|}
\hline \multicolumn{1}{|c|}{ Estilos de aprendizagem do novo milênio } & \multicolumn{1}{|c|}{$\begin{array}{l}\text { Estilos de aprendizagem do milênio } \\
\text { anterior }\end{array}$} \\
\hline $\begin{array}{l}\text { Fluência em múltiplas mídias; valoriza cada uma em } \\
\text { função dos tipos de comunicação, atividades, } \\
\text { experiências e expressões que ela estimula. }\end{array}$ & $\begin{array}{l}\text { Centra-se no trabalho com uma mídia única, } \\
\text { mais adequada ao estilo e às preferências do } \\
\text { indivíduo. }\end{array}$ \\
\hline $\begin{array}{l}\text { Aprendizado baseado em experiências de pesquisa, } \\
\text { peneira e síntese coletiva, em vez da localização e } \\
\text { absorção de informações em alguma fonte individual } \\
\text { melhor; prefere aprendizado comunal em experiências } \\
\text { diversificadas, tácitas e situadas; valoriza o } \\
\text { conhecimento distribuído por uma comunidade em um } \\
\text { contexto, assim como o conhecimento de um indivíduo. }\end{array}$ & $\begin{array}{l}\text { Integração individual de fontes de informação } \\
\text { explícitas e divergentes. }\end{array}$ \\
\hline $\begin{array}{l}\text { Aprendizado ativo baseado na experiência (real e e } \\
\text { simulada) que inclui oportunidades frequentes para } \\
\text { reflexão (por exemplo, infundindo experiências na } \\
\text { simulação Virtual University, em um curso sobre } \\
\text { lideraça em universidade); valoriza estruturas de } \\
\text { referência bicêntricas (em que é possível enxergar os } \\
\text { objetos por dentro e por fora) e imersivas que infundam } \\
\text { orientação e reflexão no aprendizado pelo fazer. }\end{array}$ & $\begin{array}{l}\text { Experiências de aprendizagem que separam } \\
\text { ação e experiência em fases distintas. }\end{array}$ \\
\hline $\begin{array}{l}\text { Expressão por meio de teias não lineares e associativas } \\
\text { de representações em vez de histórias lineares (por } \\
\text { exemplo, criar uma simulação e uma página Web para } \\
\text { expressar a compreensão em vez de escrever um artigo); } \\
\text { usa representações envolvendo simulações ricamente } \\
\text { associadas e situadas. }\end{array}$ & $\begin{array}{l}\text { Usa multimídia ramificada, mas altamente } \\
\text { hierárquica. }\end{array}$ \\
\hline $\begin{array}{l}\text { Codesign de experiências de aprendizado } \\
\text { personalizadas para necessidades e preferências } \\
\text { individuais. }\end{array}$ & $\begin{array}{l}\text { Enfatiza a seleção de uma variante } \\
\text { precustomizada de uma gama de serviços } \\
\text { oferecidos. }\end{array}$ \\
\hline
\end{tabular}

Quadro 1. Estilos de aprendizagem, extraído de Mattar (2010, p. 13).

Essa geração de alunos cresceu cercada por aparatos tecnológicos, e aprendeu desde cedo a utilizá-los. São fluentes nessas múltiplas mídias, processam informações de forma rápida e esperam retorno rápido também. São multitarefas e preferem o visual ao textual. Além disso, conforme esse autor, as experiências diversificadas, tácitas e situadas 
têm papel fundamental no processo de aprendizagem dessa geração de nativos digitais.

Jukes, McCain e Crockett (2010) também nos trazem em seu livro um quadro comparando as preferências dos Aprendizes Digitais com as preferências de muitos educadores e que, igualmente, estão em consonância com as pesquisas já apresentadas:

\begin{tabular}{|c|c|}
\hline Aprendizes Digitais preferem: & Muitos educadores preferem: \\
\hline $\begin{array}{l}\text { Receber informações rápidas, de várias fontes } \\
\text { multimídia; }\end{array}$ & $\begin{array}{l}\text { Passar informações de forma lenta e } \\
\text { controlada, de fontes limitadas; }\end{array}$ \\
\hline $\begin{array}{l}\text { Processar figuras, sons, cores e vídeos antes de } \\
\text { textos; }\end{array}$ & $\begin{array}{l}\text { Fornecer textos antes de figuras, sons, cores e } \\
\text { vídeos; }\end{array}$ \\
\hline $\begin{array}{l}\text { Acesso aleatório a informações multimídia com } \\
\text { hiperlinks; }\end{array}$ & $\begin{array}{l}\text { Ministrar informações de forma linear, lógica e } \\
\text { sequencial; }\end{array}$ \\
\hline Trabalhar em conjunto com outros; & $\begin{array}{l}\text { Que os alunos trabalhem de forma } \\
\text { independente antes de interagirem com outros; }\end{array}$ \\
\hline Aprender "na hora em que precisam", "a tempo"; & Ensinar "caso precisem"; \\
\hline $\begin{array}{l}\text { Gratificação instantânea com recompensas } \\
\text { imediatas; }\end{array}$ & Gratificações e recompensas adiadas; \\
\hline $\begin{array}{l}\text { Aprendizagem que seja relevante, ativa, útil para o } \\
\text { momento e divertida. }\end{array}$ & $\begin{array}{l}\text { Ensinar memorização para preparação para } \\
\text { testes padronizados. }\end{array}$ \\
\hline
\end{tabular}

Quadro 2. Preferências de aprendizes digitais e de educadores, traduzido e adaptado de Jukes, McCain e Crockett (2010, p. 35).

A partir desse quadro, podemos perceber que existe uma lacuna ou um distanciamento entre as preferências dos aprendizes digitais e de muitos de seus professores. A começar pela forma de se passar a informação: enquanto os alunos estão acostumados a receber informações rápidas, de várias fontes e com acesso aleatório, (como, por exemplo, quando estão conectados em uma rede social, ouvindo música, conversando com amigos por mensagens instantâneas e fazendo uma pesquisa no Google), muitos de seus professores preferem passar as informações da forma como eles receberam quando eram estudantes, de forma controlada, linear e sequencial.

Outra grande diferença é a preferência por multimídias em vez de apenas um texto. Aprendizes digitais estão acostumados com a televisão e os recursos trazidos pelo 
computador e Internet, em que eles têm contato com infográficos animados que colocam os textos em segundo plano - não é necessário ler o texto para se entender a mensagem trazida pelos gráficos, imagens, etc. Muitos educadores, por sua vez, preferem ainda trazer o texto primeiro e explorá-lo sem o auxílio dos recursos multimídia, em vez de tentar trabalhar e desenvolver esse letramento visual de seus alunos.

Outro ponto de desgaste é a escolha ou determinação do que será ensinado. Muitas escolas e professores preferem ensinar conteúdos a seus alunos pensando na possibilidade do "caso precisem", isto é, acreditam que devem ensinar todo o conteúdo que pode cair em um exame de vestibular, ou toda a matéria que poderá ser cobrada em um exame de proficiência, etc., ou seja, conteúdos gerais que muitas vezes não serão utilizados fora da sala de aula.

Enquanto isso, os aprendizes digitais preferem aprender informações na "hora em que eles precisam", isto é, conhecimento útil e prático para suas necessidades. Nas palavras dos autores, aprender "a tempo" ou "na hora em que precisam" significa possuir "as habilidades, o conhecimento e os hábitos mentais que lhes permitirão aprender e se adaptar continuamente 'a tempo", para o momento em que seja necessário ou de seu interesse (JUKES et al., 2010, p. 39) ${ }^{3}$.

Essa geração de aprendizes digitais quer que a aprendizagem seja algo útil, relevante e que esteja relacionada ao seu mundo e suas vivências, e que também seja agradável e divertida. Prensky (2001, p. 1) afirma que, em média, ao terminar a graduação, os alunos passaram menos de 5.000 horas lendo, mas mais de 10.000 horas jogando videogames, e mais de 20.000 vendo televisão. Ao mesmo tempo, terão trocado cerca de 250.000 e-mails/mensagens instantâneas além de passar mais de 10.000 horas conversando no telefone (PRENSKY, 2006). Eles estão acostumados a utilizarem celulares com vários recursos disponíveis, a empregar o computador para seus interesses, e a se comunicar e estar em contato com seus amigos, constantemente, através da tecnologia. Contudo, muitas escolas e educadores ainda não conseguiram entender e trazer isso para suas práticas e salas de aulas.

É importante ressaltar que esse conceito de "nativos digitais" e "imigrantes digitais", trazida por Prensky, não é algo universal e fixo, categorizando todos nascidos a partir do ano $\mathrm{X}$ como nativos ou imigrantes e dotados de tais características. Isso quer dizer que nem todos nascidos na era digital serão nativos ou aprendizes digitais, da mesma forma que nem todos da geração anterior serão imigrantes digitais.

Embora seja um termo bastante discutido e, muitas vezes, criticado na academia, entendo e utilizo o termo "nativo digital" da mesma forma que os autores Palfrey e Gasser (2011), reconhecendo que "não é uma questão de geração, mas enxergando os nativos digitais como uma população de jovens que utilizam a tecnologia de forma relativamente avançada, ou sofisticada ${ }^{4}$ "(PALFREY; GASSER, 2011, p. 188).

\footnotetext{
${ }^{3}$ Versão para: Just-in-time” learning is about learners having the skills, knowledge, and habits of mind that will allow them to continuously learn and adapt "just in time", when that next window of opportunity or area of interest briefly opens to them.

${ }^{4}$ Versão para: We identify digital natives as a population, and not a generation, of young people who use technology in relatively advanced ways.
} 
De acordo com esses autores, esse é o fator principal para ser considerado um nativo digital: ser capaz de utilizar as tecnologias digitais de formas sofisticadas. Essa capacidade estaria relacionada a certo nível de letramento digital e as habilidades envolvidas nesse processo, que seriam:

[...] habilidades analíticas que permitem aos jovens distinguir situações que podem ser perigosas para eles de situações sociais comuns com colegas; localizar e reconhecer informações de alta qualidade; administrar sua própria identidade e como ela é formada através do compartilhamento de informações seletivas e configurações de privacidade nas redes sociais; e assim por diante ${ }^{5}$. (PALFREY; GASSER, 2011, p. 189)

Ou ainda, como o próprio Prensky (2011) menciona, essa distinção é mais sobre cultura do que sobre habilidades ou conhecimentos sobre o universo digital. Nas palavras do autor:

Trata-se do conforto das pessoas mais jovens com a tecnologia digital, sua crença na facilidade, na utilidade, na benignidade e na visão da tecnologia como um "parceiro" divertido que eles podem dominar, sem muito esforço, se forem expostos ou se optarem por fazê-ló ${ }^{6}$. (PRENSKY, 2011, p. 17)

A ideia em xeque é mais que simplesmente uma geração que já nasceu imersa nesse mundo tecnológico, mas trata, também, da questão da "sabedoria digital", conceito trazido por Prensky em sua obra From digital natives to digital wisdom (2012). Ser considerado um nativo digital envolve não apenas o manuseio da tecnologia com facilidade, mas implica em usuários que são capazes de tomar decisões sábias com base nessa tecnologia e também a utilizam para facilitar suas vidas, e não podemos, absolutamente, categorizar ou generalizar afirmando que todos os nascidos nessa era digital terão esse conhecimento, ou que os nascidos anteriormente não.

Além disso, temos também a questão das desigualdades sociais. Apesar de toda a expansão da tecnologia e da maior facilidade de acesso à Internet, ainda existem muitas pessoas que não possuem esse acesso e que não estão conectadas nem vivendo esse mundo tecnológico. Contudo, apesar dessa diferença e desse distanciamento existir, temos visto que mesmo em meio às dificuldades, a tecnologia está se fazendo presente nos mais variados contextos. Tratando especificamente da realidade de minha pesquisa de mestrado, que se deu em uma escola pública de periferia da cidade de Uberlândia, pude constatar que todos os alunos envolvidos na pesquisa possuíam computadores e/ou smartphones com acesso à Internet.

Entendemos que o ser humano é um ser complexo em sua natureza, e nem todos os educandos se enquadram nesse panorama de aprendizes digitais. Entretanto, temos

\footnotetext{
${ }^{5}$ Tradução de: These skills relate to analytical abilities that enable a young person to distinguish situations that may prove dangerous to them from those that are ordinary social situations with peers; to locate and recognize high-quality information; to manage their own identity as it forms through the use of selective information sharing and privacy settings on social network site; and so forth.

6 Tradução de: It is about younger people's comfort with digital technology, their belief in its ease, its usefulness, and its being generally benign, and about their seeing technology as a fun "partner" that they can master, without much effort, if they are shown or choose to.
} 
percebido cada vez mais em nossos alunos a mudança comportamental causada pela inserção dos recursos tecnológicos em suas vidas. Seria um equívoco menosprezar todo o conhecimento e vivência tecnológica que esses estudantes possuem, ou mesmo não fazer uso desse conhecimento e dos recursos que a tecnologia nos proporciona. Precisamos aprender a utilizá-la em nosso favor, como uma ferramenta para auxiliar no processo de ensino e aprendizagem.

É possível que grande parte da responsabilidade do fracasso escolar que temos experimentado nos últimos anos se deva a esse fator. Questões de indisciplina, falta de interesse e motivação com os estudos podem estar relacionadas ao fato de que a realidade das escolas hoje tem se distanciado da realidade da sociedade. Freire (2009, p. 16) menciona que

escola e sociedade parecem não caminhar na mesma direção nem falar a mesma língua: a escola mostra-se previsível, normativa, priorizando uma linguagem prescritiva, atuando em via de mão única, perpetuando a transmissão de conhecimento disciplinar e fragmentado. A sociedade, ao contrário, é dinâmica, multimidiática e imprevisível, priorizando a multiplicidade e simultaneidade de linguagens, valorizando $o$ conhecimento em rede, transdisciplinar, construído, coconstruído, desconstruído e dinamicamente reconstruído a todo momento e ao longo da vida.

Essa percepção da autora retrata bem o que foi dito por Prensky (2001), quando ele trata da necessidade dos nativos digitais terem que aprender com professores que são imigrantes digitais, com uma linguagem completamente diferente uma da outra: "instrutores Imigrantes Digitais, que falam uma língua ultrapassada (da era pré-digital), estão lutando para ensinar uma população que fala uma língua completamente nova" (PRENSKY, 2001, p. 2).

Jukes, McCain e Crockett (2010) também afirmam que as crianças dessa nova geração são diferentes. Segundo os autores,

as crianças de hoje são fundamentalmente diferentes em sua forma de pensar; em sua forma de acessar, absorver, interpretar, processar e usar informação; e em sua forma de ver, interagir e se comunicar no mundo moderno - e que essas diferenças, em grande parte, são devidas às suas experiências com as tecnologias digitais ${ }^{8}$. (JUKES; MCCAIN; CROCKETT, 2010, p. 20)

Ainda de acordo com esses mesmos autores, essas diferenças são decorrentes da neuroplasticidade ${ }^{9}$ do cérebro humano, que se reorganiza e se transforma de acordo com

\footnotetext{
${ }^{7}$ Tradução para: our Digital Immigrant instructors, who speak an outdated language (that of the pre-digital age), are struggling to teach a population that speaks an entirely new language.

8 Tradução para: children today are fundamentally different in the way they think; the way they access, absorb, interpret, process and use information; and in the way they view, interact and communicate in the modern world - and that these differences are due in large part to their experiences with digital technologies.

${ }^{9}$ De acordo com a Wikipédia, neuroplasticidade "refere-se à capacidade do sistema nervoso de mudar, adaptar-se e moldar-se a nível estrutural e funcional ao longo do desenvolvimento neuronal e quando sujeito
} 
as experiências que vivemos, bem como de acordo com a intensidade e duração dessas experiências. Isso significa que dependendo da atividade que é feita com mais regularidade ou por mais tempo (por exemplo, esportes, leitura ou jogos de videogames), o indivíduo estará estimulando e, consequentemente, criando, novas conexões neurais.

Jukes et al. (2010, p. 21) citando Johnson (2005) argumentam que devido à grande exposição a esse mundo digital, as crianças dessa nova geração chegam às escolas com um conjunto de hábitos e habilidades cognitivas completamente diferente das crianças da geração anterior, e que seus dispositivos tecnológicos se tornaram extensões de si mesmos, sendo um acessório social e de aprendizagem indispensável ${ }^{10}$. Devido às novas conexões formadas pela vivência e exposição aos recursos tecnológicos, as crianças têm aprimorado suas habilidades de processamento e memória visual, criando e recriando conexões em seus cérebros de forma contínua e este fato contribui para a mudança na forma de aprender desses alunos (JUKES et al., 2010, p. 25).

Em consequência dessas mudanças no cérebro, Jukes et al. (2010, p. 27 e 28), baseados em outras pesquisas, nos mostram que enquanto pessoas das gerações anteriores leem uma página passando os olhos por ela com um movimento parecido com um Z, a geração digital o faz com um movimento de F, ignorando o que está escrito do lado direito e na parte inferior da página, a não ser que tenham algum estímulo para prestar atenção nelas. Eles mostram também que esses leitores tendem a focar nas partes destacadas com cores vivas, prestando mais atenção nas informações dessas áreas. Isso porque "pelo menos $60 \%$ dos alunos em qualquer sala de aula [...] são aprendizes visuais ou sinestésicos, ou uma combinação dos dois" (ERIC JENSEN, 2008, apud JUKES et al., 2010, p. 28).

Em razão de todas essas transformações, há a necessidade de se pensar em formas de ensino que aliem essas duas gerações, para tentarmos melhorar os processos de ensino/aprendizagem e os resultados que temos obtido. Muitos professores se queixam que seus alunos estão desinteressados ou desmotivados, que não memorizam informações e não participam ativamente das aulas, mas não percebem que eles mesmos, muitas vezes, não se esforçam para tentar trabalhar de forma a envolver esses alunos.

Reconhecer que nossos alunos estão mudando sua forma de pensar e de aprender é um primeiro passo para tentarmos melhorar nossas práticas docentes. É necessário refletir sobre como podemos transformar as escolas e sistemas de ensino, como aliar a utilização desses recursos tecnológicos com os conteúdos que precisamos ensinar, e como fazer isso de forma proveitosa e significativa, tanto para professores quanto alunos.

\section{Ensino de línguas mediado pelo computador e sua normalização}

Baseados nessa necessidade de se repensar o ensino, surgiram os estudos sobre o

\footnotetext{
a novas experiências”.(NEUROPLASTICIDADE Em: Wikipédia, a enciclopédia livre. Disponível em https://pt.wikipedia.org/wiki/Neuroplasticidade. Acesso em 04 de outubro de 2016).

${ }^{10}$ Versão para: As a result of digital bombardment, children today arrive in the classroom with a completely different set of cognitive skills and habits than past generations had and that their devices have become extensions of themselves, indispensable social and learning accessories.
} 
ensino de línguas mediado por computador (em inglês, Computer Assisted Language Learning - CALL). Esse campo de estudos, já com mais de quatro décadas de história, nos mostra as transformações que têm ocorrido em nosso mundo, tanto em questões linguísticas, quanto tecnológicas (SOUZA, 2004).

É fato que a tecnologia tem afetado a forma como o ensino de línguas vem acontecendo. Levy e Stockwell (2006), refletindo sobre o tema, argumentam que:

o CALL inicial consistia em alunos que trabalhavam em tarefas simples atribuídas pelo professor individualmente ou em pequenos grupos, e palavras como "aprendizagem colaborativa" e "bate-papo" tinham significados bastante diferentes do que vieram a significar após o advento da Internet. Além disso, antes da Internet, os professores não precisavam saber como o e-mail, o bate-papo, o áudio e a videoconferência contrastavam com o ensino presencial, a comunicação telefônica, e assim por diante. Assim, o desenvolvimento de novas tecnologias dá origem a modos de pensar e de comunicar completamente novos e a áreas de pesquisa que não poderiam ter existido sem tais tecnologias ${ }^{11}$. (LEVY; STOCKWELL, 2006, p. 206)

A Internet foi uma das responsáveis pelas transformações que temos visto e vivenciado. Ela é um marco divisor, não apenas em relação aos avanços e mudanças nos softwares, mas ela também marca uma transformação nos modos de ensinar, em se tratando de pedagogias e/ou metodologias.

Em meados da década de 90, um grupo de pesquisadores, conhecido como New London Group (doravante NLG), percebeu que essas mudanças causadas pelas novas tecnologias estavam afetando a vida das pessoas como um todo: questões de globalização e acesso a informações causavam mudanças nas relações sociais estabelecidas até então. Dessa forma, era necessário um termo que abarcasse essa diversidade cultural, linguística e tecnológica que se faz presente em nosso mundo, considerando a cultura e o contexto como elementos fundamentais no processo de significação.

Isto posto, o grupo cunhou o termo Multiliteracies ${ }^{12}$, traduzido como Multiletramentos, por entenderem que o termo letramento, no singular, abarcava um conceito formal, monolíngue e monocultural, governado por regras e padrões bem definidos para a linguagem e que não era suficiente para a conjuntura em que estavam vivendo. De acordo com o NLG (1996, p. 64),

a pedagogia dos multiletramentos, por outro lado, concentra-se em modos de representação muito mais amplos do que apenas a língua. Estes diferem de acordo com a cultura e contexto, e têm efeitos cognitivos, culturais e sociais específicos. (...) Multiletramentos

\footnotetext{
11 Tradução para: Early CALL consisted of learners working on simple tasks assigned by the teacher individually or in small groups, and words such as "collaborative learning" and "chat" held rather different meanings from what they came to mean after the advent of the Internet. In addition, before the Internet, teachers did not need to know how e-mail, chat, and audio- and videoconferencing contrasted with faceto-face teaching, telephone communication and so on. Thus, the development of new technologies gives rise to completely new ways of thinking and communicating, and areas of research that could not have existed without such technologies.

${ }^{12}$ Disponível no artigo "A pedagogy of multiliteracies: designing social futures", de 1996.
} 
também criam um tipo diferente de pedagogia, na qual a linguagem e outros modos de significação são recursos de representação dinâmicos, sendo constantemente refeitos por seus usuários enquanto trabalham para atingir seus diversos fins culturais ${ }^{13}$.

Podemos depreender, a partir dessa definição, a necessidade de se relacionar a linguagem em uso e as práticas sociais. Conforme apontado por Magnani (2011, p. 3), "as práticas de linguagem dos sujeitos em análise possuem estrita relação com o contexto ao qual ele é exposto" e, ainda,

de um ponto de vista linguístico e semiótico, o grande mérito dessas novas propostas [dos Novos Letramentos e dos Multiletramentos] consiste em chamar a atenção para o fato de que a relação com a língua e o aprendizado de linguagens não é algo abstrato, mas diversificado e dependente do contexto cultural. (MAGNANI, 2011, p. 4)

Consequentemente, percebemos o papel ativo que o sujeito, no caso o aluno, deve desempenhar no processo de significação. É a partir de suas práticas situadas que ele irá construir os significados, seja de um texto impresso ou de um game on-line, sem esquecer-se do papel de transformação que ele pode exercer sobre os meios em que vive e convive.

A partir de todas essas mudanças que presenciamos em nossa sociedade, constatamos uma necessidade de ensinar nossos alunos não apenas a ler, escrever e resolver problemas matemáticos. É preciso letrá-los para esse mundo digital em que estão inseridos. Isso porque percebemos que apesar de terem a tecnologia a sua disposição, e estarem constantemente conectados com seus pares, compartilhando fotos e informações, muitas vezes os estudantes não conseguem utilizar essa mesma tecnologia para propósitos acadêmicos.

Falta-lhes o conhecimento, a criticidade, para realizar pesquisas na Internet e encontrar resultados que sejam adequados e satisfatórios. Mais ainda, falta-lhes o conhecimento sobre como aproveitar os resultados de suas buscas e transformá-los em um trabalho crítico e reflexivo, que possa ser entregue aos professores, carregando não apenas uma cópia extraída da Internet, mas um trabalho que expresse sua visão do conteúdo e que dialogue com a teoria apresentada.

Conforme Pegrum (2009, p. 43), é preciso fazer uma distinção entre ser techcomfy e tech-savvy. Para o autor, tech-comfy são aqueles que conseguem utilizar a tecnologia com fins sociais ou para entretenimento, enquanto tech-savvy são os que conseguem utilizar a tecnologia de forma crítica, para fins educacionais e/ou profissionais. Nesses termos, concluímos que grande parte de nossos alunos são techcomfy, ou seja, estão familiarizados com a tecnologia e seu uso cotidiano, porém poucos são tech-savvy, utilizando os recursos tecnológicos de forma crítica e efetiva com fins acadêmicos.

\footnotetext{
13 Tradução para: A pedagogy of multiliteracies, by contrast, focuses on modes of representation much broader than language alone. These differ according to culture and context, and have specific cognitive, cultural and social effects. (...) Multiliteracies also creates a different kind of pedagogy, one in which language and other modes of meaning are dynamic representational resources, constantly being remade by their users as they work to achieve their various cultural purposes.
} 
Contudo, essa classificação e distanciamento não ocorrem apenas para os alunos. É preciso refletir também sobre questões de formação de professores, e como capacitálos para atuarem com os recursos tecnológicos a seu favor, visando não apenas a inclusão da tecnologia em sala de aula, mas sim buscando aproveitar a vasta gama de opções que ela nos traz e nos possibilita como educadores, para contribuir com a formação de cidadãos críticos e aptos a interagir, se comunicar e transformar o mundo em que vivem.

Portanto, compreender um pouco mais sobre o letramento digital pode contribuir para a formação de professores e alunos, ao se tratar de tecnologia em sala de aula e de como utilizá-la de forma a atingir uma aprendizagem significativa, aproveitando o potencial que os tech-comfy possuem para se tornarem tech-savvy. No artigo intitulado "Letramento digital e formação de professores", Souza (2007) nos traz uma definição de letramento digital:

Em suma, entendemos letramento digital como o conjunto de competências necessárias para que um indivíduo entenda e use a informação de maneira crítica e estratégica, em formatos múltiplos, vinda de variadas fontes e apresentada por meio do computador, sendo capaz de atingir seus objetivos, muitas vezes compartilhados social e culturalmente. (SOUZA, 2007, p. 60)

Nessa definição, é reforçado o papel de agência e criticidade que o indivíduo deve assumir, já que ele deve ser capaz de tomar decisões, reconstruir e transformar os sentidos em um processo contínuo, através dos diversos recursos semióticos a ele disponíveis, em conformidade também com o que foi apontado por Magnani (2011).

Esse conceito vem ao encontro do que tenho discutido, considerando a importância do contexto e da criticidade, compreendendo que as práticas de letramentos sofrem variações de acordo com fatores externos bem como por influência social. Conforme apontado por Magnani (2014), essa perspectiva do letramento plural, crítico e transformativo poderia:

auxiliar a se entender melhor as práticas do sujeito que frequenta a sala de aula e quais as relações que ele constrói com esse aprendizado extraescolar: mais do que assumir o videogame como inspiração para a sala de aula, pode-se procurar compreender melhor quais os conflitos existentes entre sujeitos também formados por essas novas práticas e o que se espera do ensino formal. (MAGNANI, 2014, p. 58)

Neste trecho, o autor evidencia a necessidade de se repensar tanto o perfil de nossos alunos, como também o papel das escolas no processo de ensino e aprendizagem, reconhecendo que o ambiente formal de instrução não é o único capaz de ensinar. Pelo contrário, a aprendizagem extraescolar tem se mostrado, muitas vezes, mais estimulante, desafiadora e eficiente para os aprendizes atuais.

Trabalhar a partir da ótica dos multiletramentos pode contribuir para que alcancemos uma melhora nos processos educacionais, visto que ele reforça o papel de agência necessário aos indivíduos, bem como a visão crítica e estratégica da informação exigida para a atualidade. Essas competências colaboram não apenas com o rendimento escolar, mas também com a inclusão do cidadão nessa sociedade informatizada e global. 
Todas essas evoluções e transformações que vem acontecendo em nossa sociedade nos mostram que há uma grande variedade de recursos e possibilidades para se repensar a forma como ensinamos. Não estamos querendo dizer que uma forma é melhor que outra, mas que existem possibilidades diferentes, e cada uma se adapta melhor a certas realidades.

Com tantas possibilidades, cabe ao professor determinar o que ele irá utilizar em suas aulas, mas mais que isso, ele deve estar ciente do por que escolher determinado software. O professor deve ter em mente os objetivos de sua aula e buscar utilizar as ferramentas que serão mais adequadas para aquela atividade ou conteúdo, utilizando-se da tecnologia como um meio e não um fim por si só. Levy e Stockwell (2006) trazem uma citação interessante de Nelson e Oliver (1999):

não deveríamos usar um computador apenas porque é recomendado, e não deveríamos usar tecnologias mais avançadas (isto é, complicadas) quando algo mais simples dá conta da tarefa. Cada avanço tecnológico (desde o papel e caneta) cria diferentes oportunidades para a aprendizagem, e favorece diferentes estilos de aprendizagem e ensino. O computador pode ou não ser melhor do que ensinar em um quadro negro; tudo depende do que o professor quer que os alunos aprendam e de como eles planejam ensinar ${ }^{14}$. (NELSON; OLIVER, 1999, apud LEVY; STOCKWELL, 2006, p. 217)

Sendo assim, é preciso reconhecer que o ensino mediado pelo computador não será a solução para os inúmeros problemas enfrentados em uma sala de aula. Usar a tecnologia apenas porque é indicado, sem uma preparação prévia, ou sem objetivos claros e bem definidos, provavelmente não terá resultados positivos no processo de aprendizagem dos alunos. Da mesma forma, utilizar os recursos tecnológicos digitais como uma simples substituição do lápis e papel também pode não apresentar vantagens significativas.

Isso porque o uso de computadores no ensino de línguas ainda não está totalmente normalizado no ambiente escolar. Bax (2003, p. 23) afirma que "a normalização é quando uma tecnologia é invisível, dificilmente sendo reconhecida como uma tecnologia, considerada natural na vida cotidiana ${ }^{15}$ ", além de contribuir positivamente para $\mathrm{o}$ processo de ensino e aprendizagem. Para o autor, somente atingiremos a normalização do ensino de línguas mediado pelo computador quando os computadores forem

[...] usados todos os dias por estudantes de línguas e professores como parte integrante de cada lição, como uma caneta ou um livro. Professores e alunos irão usá-los sem medo ou inibição, e igualmente sem um respeito exagerado pelo que podem fazer. Eles não vão ser o centro de qualquer lição, mas eles vão desempenhar um papel em quase todas as lições. Eles serão completamente integrados em todos os outros

\footnotetext{
${ }^{14}$ Versão para: We should not be using a computer just because we should and should not be using more advanced (i.e., complicated) technologies when something simpler will do. Each technological advancement (since the paper and pen) creates different venues for learning, and supports different learning and teaching styles. The computer may or may not be better than teaching on a black-board; it all depends on what the teacher wants students to learn and how they plan to teach.

${ }^{15}$ Versão para: Normalisation is therefore the stage when a technology is invisible, hardly even recognised as a technology, taken for granted in everyday life.
} 
aspectos da vida da sala de aula, juntamente com livros didáticos, professores e blocos de notas. Eles passarão quase despercebidos ${ }^{16}$. (BAX, 2003, p. 23-24)

Ou seja, CALL somente estará normalizado em nossas aulas quando os objetivos educacionais e as necessidades dos alunos forem mais importantes que o uso da tecnologia em si (BAX, 2003), isto é, quando os computadores e os recursos digitais forem utilizados para sanar essas necessidades dos aprendizes, sem uma admiração excessiva (acreditando que a tecnologia seria uma solução mágica para os problemas) e também sem um medo exagerado (acreditando, por exemplo, que os computadores iriam substituir completamente os professores).

Bax (2011) reflete sobre esse conceito de normalização trazido por ele próprio, em 2003, a partir de uma perspectiva neo-vygotskiana, demonstrando que a atividade de aprender ou ensinar línguas através da tecnologia é: baseada na cultura; um processo social; desenvolvida através da comunicação; entendida através de cenários culturalmente formados; e desenvolvida através de assistência ou instrução (BAX, 2011, p. 7-8).

Sendo assim, percebemos a relevância da cultura e do contexto e a influência que exercem no processo de ensino e aprendizagem. Isso nos mostra que, antes de assumirmos as tecnologias digitais como a solução para a sala de aula, devemos questionar seu real potencial para nosso contexto específico, realizando o que Bax (2011) chama de "Auditoria de Necessidades ${ }^{17}$ ", para verificar se "a tecnologia é de fato necessária e útil" (BAX, 2011, p. 8) em nossos distintos ambientes.

Essa verificação da real utilidade das tecnologias digitais em nossos contextos nos auxilia a focar a aprendizagem e não mais a ferramenta tecnológica, conforme Bax (2011), o que contribuiria para o sucesso da normalização da tecnologia em sala de aula. $\mathrm{O}$ autor ainda ressalta que o foco dessa auditoria de necessidades deve ser a aprendizagem e não o aprendiz, contrapondo a ideia de Prensky (2001) de que os professores deveriam se adaptar completamente às preferências de seus alunos. Em suas palavras:

não basta que os educadores limitem-se a moldar suas práticas para atender o aluno conforme Prensky (2001) apresenta, em vez disso, precisamos focar o aprendizado. A diferença é que o foco na aprendizagem, em oposição ao aprendiz, pode, frequentemente, envolver desafiar o que o aluno afirma, acredita e quer, ao invés de simplesmente se acomodar a ele. Sem esse elemento de desafio, o aluno nunca poderia romper com preconceitos e elevar-se a níveis mais críticos de pensamento e análise ${ }^{18}$. (BAX, 2011, p. 9)

\footnotetext{
${ }^{16}$ Versão para: CALL will reach this state when computers (probably very different in shape and size from their current manifestations) are used every day by language students and teachers as an integral part of every lesson, like a pen or a book. Teachers and students will use them without fear or inhibition, and equally without an exaggerated respect for what they can do. They will not be the centre of any lesson, but they will play a part in almost all. They will be completely integrated into all other aspects of classroom life, alongside coursebooks, teachers and notepads. They will go almost unnoticed.

${ }^{17}$ 'Needs Audit' - conforme Bax (2011, p. 8).

${ }^{18}$ Versão para: it is not enough for educators merely to shape their practice to fit the learner in the way Prensky (2001) prefers, but we need instead to focus on learning. The difference is that a focus on learning as opposed to the learner might frequently involve challenging what the learner states, believes and wants,
} 
Sendo assim, reforço a necessidade de se repensar o ensino e as escolas. Temos condições para tanto. Não apenas para que o uso das tecnologias digitais seja normalizado, ou para que as escolas se adaptem à realidade digital do mundo fora dela, mas para que tenhamos conteúdos significativos, que os estudantes realmente aprendam e não somente decorem, e que seja conhecimento útil e não apenas informação solta.

O grande desafio é aliar o incentivo de políticas públicas (para revisão curricular e investimentos, tanto na educação básica quanto no ensino superior) às ações que tornariam tudo isso possível. Contudo, para que isso ocorra, é necessária a mudança de mentalidade daqueles que são responsáveis pela educação em todos os níveis, isso inclui: governantes - com investimentos em infraestrutura e apoio às escolas; universidades reformulando currículos das licenciaturas, de forma a trabalhar com e sobre as tecnologias digitais; gestores escolares - em parceria com as universidades, propondo cursos de capacitação para professores em serviço, bem como apoiando e incentivando a inserção e uso de recursos tecnológicos nas escolas; professores - buscando capacitação e formas de contribuir para que tenhamos um ensino com conteúdos relevantes e significativos; estudantes, pais e toda a comunidade envolvida nesse processo - para que se envolvam nas atividades escolares e reconheçam que têm um papel ativo a ser exercido, agindo para transformar suas realidades.

\section{Resultados da pesquisa - Jogos digitais: uma experiência de aprendizagem de língua inglesa em uma escola pública}

Em minha pesquisa de mestrado, busquei analisar as potencialidades do uso de jogos digitais para a aprendizagem de língua inglesa, com alunos dos $8^{\circ}$ e $9^{\circ}$ anos do ensino fundamental de uma escola pública de Uberlândia. Mais especificamente, os objetivos eram: mapear as concepções dos alunos a respeito da inserção e utilização de jogos e recursos tecnológicos nas aulas de inglês; analisar de que forma a inserção de jogos digitais nas aulas de língua inglesa pode influenciar nas oportunidades de aprendizagem dos alunos; e, por fim, identificar o que seria possível aprender sobre a língua inglesa através do jogo digital.

A partir das análises realizadas, pude confirmar que os alunos se encaixam no perfil de nativos digitais, conforme proposto por Prensky. Todos eles possuíam acesso a diversos dispositivos tecnológicos, bem como à Internet. Além disso, podem ser considerados techcomfy (PEGRUM, 2009), pois estão bem familiarizados com os recursos digitais e apreciam utilizá-los. Contudo, muitos deles ainda não conseguem utilizar a tecnologia com outros fins, que não o de entretenimento.

Verifiquei, também, que os estudantes consideram muito importante a utilização de recursos tecnológicos, não apenas nas aulas de língua inglesa, mas também em todas as outras disciplinas, pois, segundo eles, as tecnologias digitais podem proporcionar aulas mais diferentes e atrativas. Isto é, têm o potencial de despertar neles o interesse pelo conteúdo, e os estimula a participarem ativamente das atividades propostas. Por essa fala, pude confirmar que as tecnologias digitais ainda não estão normalizadas na escola. $\mathrm{O}$

rather than simply accommodating to it. Without this element of challenge the learner can never break away from preconceptions and rise to more critical levels of thinking and analysis. 
simples fato de os alunos terem de se locomover da sala de aula, do andar superior, para o laboratório de informática já causa certo transtorno, e é estranho à sua rotina, já que poucos professores utilizam os computadores em suas aulas. Talvez, esse seja um dos motivos pelo grande interesse dos alunos em participar deste projeto de pesquisa. A esses aprendizes, pareceu algo excepcional a possibilidade de jogarem, durante as aulas, um jogo não-educacional e que eles conheciam de fora da escola.

Contudo, apesar desse estranhamento e de alguns não os utilizarem com essa finalidade, todos os alunos-participantes afirmaram acreditar ser possível aprender através de jogos e de recursos tecnológicos. Destacaram, também, que esse uso pode beneficiar o processo de ensino e aprendizagem, pois desperta o interesse dos mesmos e prende sua atenção, motivando-os e proporcionando oportunidades significativas de aprendizagem.

Percebi que o uso do jogo digital com os alunos-participantes dessa pesquisa influenciou positivamente em suas oportunidades de aprendizagem, pois o interesse e apreço desses participantes pelo jogo levaram-nos a buscarem formas de melhorar a sua compreensão da língua-alvo. Como tudo no jogo estava em língua inglesa e os outros jogadores conversavam em inglês, essa imersão na língua proporcionada pelo jogo fez com que eles passassem a refletir sobre possíveis estratégias e práticas que pudessem contribuir com seu desenvolvimento linguístico, de forma a atingir um melhor desempenho no jogo. Tais estratégias iam além da mera tradução das histórias através de ferramentas como o Google tradutor. Notei que esses alunos passaram a se esforçar mais para alcançarem essa aprendizagem, pois, por meio das imagens e contexto do jogo, eles passaram a inferir o significado de palavras e expressões do jogo e conseguiram se comunicar com os outros jogadores de forma efetiva. Eles também começaram a praticar a leitura em língua inglesa através do site oficial, bem como através da participação em fóruns on-line e sites de vídeos a respeito do jogo, tanto na escola quanto fora dela.

Acredito que os jogos digitais, de maneira geral, possibilitam trabalhar as quatro habilidades linguísticas (compreensão oral, escrita, leitura e oralidade), bastando ao professor escolher aquele mais adequado à necessidade do momento e adaptá-lo para que sirva ao seu propósito. Existem vários recursos disponíveis e jogos que tratam dos mais variados temas. Por esse motivo, e pela capacidade que os jogos têm de estimular e manter seus jogadores interessados e envolvidos, creio que são ótimas ferramentas que ampliam as oportunidades de aprendizagem dos alunos de hoje.

Esta pesquisa possibilitou a confirmação da importância que os recursos tecnológicos, e os jogos digitais especificamente, possuem na vida de nossos alunos e a capacidade que têm de influenciar em suas oportunidades de aprendizagem da língua. Conforme citado por Gee (2005), é verdadeiro o poder que os jogos digitais possuem de estimular, provocar e motivar seus jogadores. Por este motivo, as oportunidades de aprendizagem que emergem nesse contexto possuem mais chances de se efetivarem de forma significativa para os alunos.

Acredito, também, que este trabalho forneceu subsídios para que pudéssemos refletir sobre a forma como as escolas têm funcionado em contraposição à realidade digital de seus alunos, e a forte necessidade de se repensar o modelo atual desse ambiente formal de aprendizagem, atualizando nossas metodologias e abordagens, reconceituando 
esse espaço de forma a atender às necessidades e anseios desses alunos que estão imersos no mundo digital. Não podemos ignorar o conteúdo e currículo que precisam ser ensinados, porém, enquanto a escola tentar lutar contra as tecnologias digitais em sala de aula, os resultados continuarão sendo negativos, com alunos desmotivados e desinteressados. Ao tentarmos aliar o uso dessas tecnologias aos nossos componentes curriculares, temos a oportunidade de atrair esses alunos, despertando seu interesse, de forma a torná-los participantes críticos e ativos em seu processo de aprendizagem.

\section{Referências}

BAX, S. Normalisation revisited: the effective use of technology in language education. IJCALLT, v. 1, n. 2, p. 1-15, 2011.

Call - Past, present and future. System, v.31, p.13-28, 2003.

BRASIL. Presidência da República. Secretaria de Comunicação Social. Pesquisa brasileira de mídia 2015: hábitos de consumo de mídia pela população brasileira. Brasília: Secom, 2014. Disponível em http://www.secom.gov.br/atuacao/pesquisa/lista-depesquisas-quantitativas-e-qualitativas-de-contratos-atuais/pesquisa-brasileira-de-midiapbm-2015.pdf/view. Acesso em: 02 out. 2016.

FREIRE, M.M. Formação tecnológica de professores: problematizando, refletindo, buscando. Em: SOTO, U. et al. (Orgs.). Linguagem, educação e virtualidade: experiências e reflexões. São Paulo: Cultura Acadêmica, 2009, p. 13-28.

GEE, J.P. Good video games and good learning. Phi Kappa Phi Forum, 85, n. 2, 2005.

JUKES, I.; MCCAIN, T.; CROCKETT, L. Understanding the Digital Generation: teaching and learning in the new digital landscape. British Columbia, Canada: $21^{\text {st }}$ Century Fluency Project; Corwin, 2010.

LEVY, M.; STOCKWELL, G. Call dimensions: options and issues in computer-assisted language learning. New Jersey: Lawrence Erlbaum Associates, 2006.

MAGNANI, L.H. Videogames, letramentos e construção de sentidos. In: TAKAKI, N.H.; MACIEL, R.F. (Orgs.). Letramentos em terra de Paulo Freire. Campinas: Pontes Editores, 2014. p. 43-61.

Um passo para fora da sala de aula: novos letramentos, mídias e tecnologias.

Revista X, v. 1, 2011.

MATTAR, J. Games em educação: como os nativos digitais aprendem. São Paulo: Pearson Prentice Hall, 2010.

NEW LONDON GROUP. A Pedagogy of Multiliteracies: Designing Social Futures. Harvard Educational Review, 66, 1, 60-92, 1996. Disponível em http://newarcproject.pbworks.com/f/Pedagogy\%2Bof\%2BMultiliteracies_New\%2BLon don\%2BGroup.pdf. Acesso em: 30 mai. 2016. 
PALFREY, J.; GASSER, U. Reclaiming an awkward term: what we might learn from "Digital Natives". In: THOMAS, M. Deconstructing digital natives: young people, technology, and the new literacies. New York: Routledge, 2011. p. 186-204.

PEGRUM, M. From blogs to bombs: the future of digital technologies in education. Crawley, W.A.: UWA Publishing, 2009.

PRENSKY, M. From digital natives to digital wisdom: hopeful essays for 21 st century learning. California: Corwin, 2012.

Digital wisdom and Homo Sapiens Digital. In: THOMAS, M. Deconstructing digital natives: young people, technology, and the new literacies. New York: Routledge, 2011, p. 15-29.

Don't bother me mom - I'm learning!: how computer and video games are preparing your kids for 21 st century success and how you can help. St. Paul, Minnesota: Paragon House, 2006.

Digital natives, digital immigrants. On the Horizon, v. 9, n. 5, p. 1-6, 2001.

RODRIGUES, J.J.C. Jogos digitais: uma experiência de aprendizagem de língua inglesa em uma escola pública. Dissertação. Mestrado em Estudos Linguísticos, Universidade Federal de Uberlândia, Uberlândia, 2017.

SOUZA, R.A. Um olhar panorâmico sobre a aprendizagem de línguas mediada pelo computador: dos drills ao sociointeracionismo. Fragmentos, Florianópolis, n. 26, p. 7386, jan/jun. 2004.

SOUZA, V.V.S. Letramento digital e formação de professores. Revista Língua Escrita, Belo Horizonte, n. 2, 55-69, 2007. Disponível em http://www.ceale.fae.ufmg.br/app/webroot/files/uploads/revista\%20lingua\%20escrita/Li nguaEscrita_2.pdf. Acesso em: 01 jun. 2016.

Artigo recebido em: julho de 2017.

Aprovado e revisado em: outubro de 2017.

Publicado em: novembro de 2017.

Para citar este texto:

RODRIGUES, Jeanne Jesuíno Cardoso. A influência das tecnologias digitais nos processos de ensino e aprendizagem de línguas. Entremeios [Revista de Estudos do Discurso, on-line, www.entremeios.inf.br], Seção Temática [Linguagem e Tecnologia], Programa de Pós-Graduação em Ciências da Linguagem (PPGCL), Universidade do Vale do Sapucaí (UNIVÁS), Pouso Alegre (MG), vol. 15, p. 301-318, jul. - dez. 2017. DOI: http://dx.doi.org/10.20337/ISSN2179-3514revistaENTREMEIOSvol15pagina301a318 